\title{
Life as a doctor in the Royal Navy
}

\author{
Helen Jones \\ London, UK
}

Life as a doctor in the Royal Navy is incredibly varied and no two days are the same. You could be working on shore providing daily GP care to your colleagues or be the only doctor on board a ship searching for pirates in the Indian Ocean. You could be contributing humanitarian medical support in the Caribbean following a hurricane or dealing with casualties in a helicopter search and rescue operation.

\section{New entrants}

All fully qualified doctors spend their first six months in the navy completing the new entry medical officer course, which provides specialist training in areas such as battlefield advanced trauma life support and pre-hospital care techniques-things that most civilian doctors don't get to learn.

Doctors are then streamed into the three different branches of the Royal Navy - surface fleet, submarines, or the Royal Marines. Where any doctor ends up working will depend on preferences and where they are needed. To be a doctor in the Royal Marines, and take part in front line combat, you need to pass the gruelling all arms commando course.

\section{General duties medical officers}

Having been streamed, the next three years are spent as a general duties medical officer, developing skills in applying your medical knowledge in sometimes challenging conditions. As well as working on shore, general duties medical officers can be deployed on a ship or submarine or with the Royal Marines, anywhere in the world.

As often the only doctor on a ship or submarine, general duties medical officers deal with several hundred patients and a wide range of medical needs. The Royal Navy says that its doctors often cope with a greater degree of responsibility than their peers in the NHS as they work without direct supervision.

A doctor in the Royal Navy could be dealing with a casualty from hostilities, a broken leg from an accident aboard ship, or acute appendicitis. Thinking on your feet is a must as the only help may be at a hospital hundreds of miles away and the only support available is advice from senior medical specialists by email or satellite phone.

After spending three years as a general duties medical officer, you can then choose to specialise, just as you would in civilian medicine.

\section{Contrast with civilian work}

Some of the work on board involves dealing with occupational health problems to a greater degree than as a civilian doctor. It is essential that the crew is as healthy as possible so they can carry out their duties. A pilot on board an aircraft carrier, for example, may not be able to fly if he or she is suffering from migraines and an engineer with back pain may not be able to fix vital machinery.

Keeping the ship running must be weighed against the patient's ability to do the job and patient confidentiality, while also ensuring that those in charge of the ship have enough information to make operational decisions and assess the risks.

General duties medical officers also spend some of their time at sea training their colleagues in basic first aid and providing more advanced training to the teams with specific responsibility for first aid. On board ship, everyone must have the skills to look after others in an emergency. In addition, unlike doctors in the NHS, Royal Naval medics often treat their friends and close colleagues, which can be an additional pressure.

\section{Down time and research}

Life on board ship does have its down time and it means that many in the Royal Navy spend time developing new skills, taking up hobbies such as learning to play a musical instrument, or devoting their hours off to further study. There are also plenty of opportunities for sport and fitness. All ships and shore bases have good sports facilities and there are opportunities to play sport for Royal Navy teams at a high level.

For many doctors, life in the Royal Navy is a chance to pursue a career in medicine while also having the opportunity to travel, to get seriously involved in sport, or take part in adventurous training, from caving and mountaineering to parachuting and jungle expeditions.

Some naval doctors also get the chance to carry out research as part of Defence Medical Services Scientific Expeditions, looking at areas such as altitude acclimatisation during expeditions in locations as extreme as the jungles of south America or the Himalayas_opportunities that aren't available in civilian medical life. 